\title{
Why do breeding frogs colonize some puddles more than others?
}

\author{
Paula Cabral Eterovick and Geraldo Wilson Fernandes
}

Ecologia Evolutiva de Herbívoros Tropicais, Caixa Postal 486, Instituto de Ciências Biológicas, Universidade Federal de Minas Gerais, 30123-970, Belo Horizonte, MG, Brasil. E-mail: eterovick@hotmail.com

\begin{abstract}
The composition of anuran communities at the Serra do Cipó (southeastern Brazil) was studied to familiarize ourselves with the species that breed in natural puddles. An experiment with artificial puddles was conducted to investigate the relationship of several physical properties of puddles to the pattern of their colonization by breeding anurans; the factors included were puddle size, permanency, $\mathrm{pH}$, distance from a colonizing source, and abundance and richness of potential tadpole predators. Estimates of anuran species richness were based on records of tadpoles and calling males; species richness was higher in puddles with more types of tadpole predators. The number of species of tadpoles was higher in less ephemeral puddles with more predator types, and the number of species of calling males was higher in puddles having greater abundances of tadpole predators. Males may not be sensitive to tadpole-predation risk when they select calling sites, and the same physical characteristics of the puddles may attract both tadpole predators and anurans. For example, puddle permanency probably is such a feature, because in the less ephemeral puddles there were more species of tadpoles, as well as greater numbers and species richness of predators.
\end{abstract}

Keywords: Anura habitat selection, tadpole predators, puddle permanency, southeastern Brazil.

\section{Introduction}

At a relatively small spatial scale, the spatial and temporal distribution of anuran populations and species during reproductive activities may be influenced by choice of oviposition site; at

Received 23.05.2001

Accepted 02.10.2001 larger scales, factors such as local extinction and recolonization, and pond succession probably are important (Marsh and Borrell, 2001). Behavior associated with selection of oviposition site contributes to spatial and temporal variation in patterns of abundance or population dynamics, and is influenced by habitat quality and interactions with conspecifics or predators (Resetarits and Wilbur, 1989; Marsh and Borrell, 2001). Some environmental 
factors known to influence habitat selection by reproducing anurans are leaf litter availability, surface area, depth of water (Marsh and Borrell, 2001), shade (Werner and Glennemeier, 1999), and water chemistry and transparency (Leuven et al., 1986; Evans et al., 1996).

Isolation of water bodies is a major factor influencing anuran distribution, especially in species with limited dispersal abilities or in species that rely on breeding habitats that vary in space and time, such as temporary puddles (Marsh et al., 1999). The time taken by Tungara frogs (Physalaemus pustulosus) to colonize available ponds increased with pond isolation at Barro Colorado Island (Marsh et al., 1999), and in areas with isolated water bodies, amphibians may not be able to avoid oligotrophic and acid waters by means of habitat selection as they do at less isolated oviposition sites (Leuven et al., 1986).

At larger spatial scales, species distribution depends on colonization abilities and successful establishment of species. Factors such as landscape patterns and proximity of suitable habitats may facilitate dispersal, whereas factors such as pond chemistry and predation pressure may cause environmental resistance and prevent recruitment (Bunnell and Zampella, 1999). Once colonization occurs, interspecific competition, predation, and pond drying may interact to produce patterns of distribution and composition of tadpole assemblages (Morin, 1983; Skelly, 1996). In southeastern Michigan, Skelly (1996) found that more permanent ponds had more predators of larger sizes and greater taxonomic diversity than did less permanent ponds. Differences in the ability of tadpoles to garner resources and avoid predation were reflected in their distributions among pond sizes: tadpoles from small, temporary sites spend more time feeding and can develop faster than tadpoles from large, permanent sites, where the larvae must spend more time hiding from predators and, as a consequence, develop more slowly (Skelly, 1997).

In temporary puddles, colonization must occur every year. Anuran species richness may be determined by site selectivity by the colonizers (which may be sensitive to variables such as pool size or potential permanency) and their ability to reach a given puddle and cope with the prevailing environmental conditions.

We determined the composition of anuran assemblages in natural temporary puddles and then tested whether puddle size, permanency, $\mathrm{pH}$, distance from a colonizer source, and abundance and richness of potential tadpole predators influenced anuran species richness in artificial puddles.

\section{Methods}

\section{Study site}

The study was conducted at the montane meadows of the Serra do Cipó $\left(19^{\circ} 12^{\prime}-19^{\circ} 20^{\prime} \mathrm{S}\right.$, $43^{\circ} 30^{\prime}-43^{\circ} 40^{\prime} \mathrm{W}, 1095-1485 \mathrm{~m}$ elevation), Minas Gerais, southeastern Brazil. Many temporary wetlands and some puddles appear during the rainy season at the site and are used by anurans during reproductive activities. The rainy season starts in October or November and ends in March.

\section{Field activities}

We studied six natural puddles (Table 1) from November 1998 to March 2000. We sampled tadpoles and calling males monthly during the rainy season and bimonthly during the dry season. One man-made puddle (Puddle 3) near the upper entrance of the National Park of the Serra do Cipó is used by some frog species and functions as a natural puddle. Tadpoles that could not be identified in the field were collected and identified by comparison with specimens housed in the collections of the Universidade Federal de Minas Gerais (UFMG), MG, Brazil, and Museu de História Natural Universidade Estadual de Campinas (ZUEC), Campinas, SP, Brazil. Specimens collected during this study were deposited in the herpetological collection of the Departmento de Zoologia of the UFMG. 

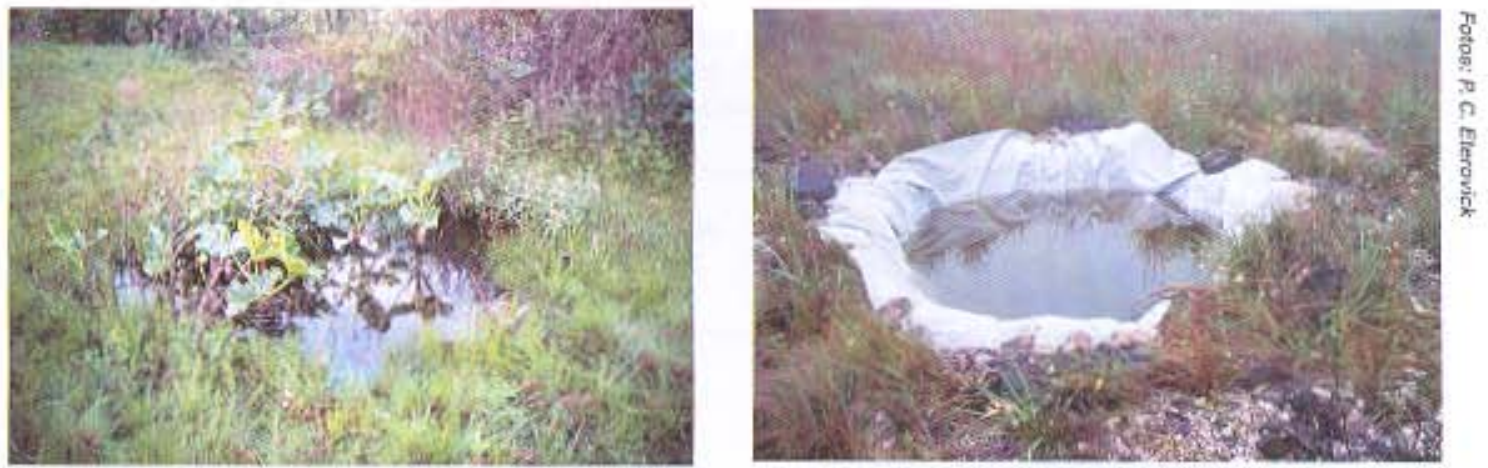

Figure 1 - Views of Puddle 4, the anuran colonizing source (A) and a 2 m-diameter artificial puddle just after lining with a plastic tarpaulin (B).

To investigate the colonizing ability of anurans that use puddles to reproduce and their preferences regarding puddle size, we dug 18 artificial puddles at increasing distances from a natural puddle (Puddle 4: Figure 1A. Table 1) that served as a colonizing source. The circular puddles were of three different sizes - $0.5,1.0$, and $2.0 \mathrm{~m}$ diameter. They had volumes of 0.05 . 0.20 , and $0.79 \mathrm{~m}^{3}$ respectively, and all were 25 $\mathrm{cm}$ deep. We positioned one puddle of each size at $5,10,20,40,80$, and $160 \mathrm{~m}$ (Table 3 ) from the source along three 160-m transects starting at the natural puddle. The angles between Transects $I$ and 2 , and 2 and 3 were about $45^{\circ}$ and $35^{\circ}$, in order to position them as far apart as possible and away from a small permanent stream that passed about $10 \mathrm{~m}$ from the source puddle. Frogs that breed in the stream do not reproduce in puddles. Therefore, we assumed that they would not interfere in the experimental colonization process. We visited these puddles once or twice a month during the rainy seasons of $1999 / 2000$ and $2000 / 2001$ until all the puddles had dried. The most distant artificial puddles dried quickly, and during the second rainy season, we attempted to prolong the duration of these puddles by lining the basins with plastic tarpaulins (Fig. IB). Most tarpaulins were stolen and only two of the smallest puddles farthest from the source that usually dried quickest after the rainy season remained intact. These were included as controls (Table 2). We measured water $\mathrm{pH}$ of natural and artificial puddles containing water on 21 November 1999 (Tables 1,2),

Potential tadpole predators were counted and identified as one of seven types - Anisoptera naiads (Odonata), water bugs (Belostomatidae), waterscorpions (Nepidae), backswimmers (Notonectidae), water scavenger bectles (Hydrophilidae), whirligig beetles (Gyrinidae), and spiders (Thaumasia Sp., Pisauridac). All of these taxa can prey upon anuran eggs and larvae (Borror et al. 1992, Roth and Jackson 1987. Sazima and Bokermann 1977. Seale 1980, A, J. dos Santos, pers, comm.). Leptodactylus labyrinthicus tadpoles feed on eggs and tadpoles of other species of anurans (M. Martins, pers. comm.). Although these tadpoles could be considered as an additional predator. we did not include them in the analyses because they only appeared in the last sampling.

\section{Statistical analyses}

We used stepwise multiple linear regressions (Systat, 1998) to relate puddle volume, permanency (number of months with water per year), $\mathrm{pH}$, distance from the colonizer source, number of tadpole predator types (richness), and total number (abundance) of potential tadpole 
Table 1 - Number of anuran species (tadpoles/calling males) found in six natural puddles at the Serra do Cipó, Southeastern Brasil from November 1998 to March 2000. The puddle used as colonizers source in the experiment with artificial pools is marked with an asterisk.

\begin{tabular}{ccccccccc}
\hline $\begin{array}{c}\text { Number of } \\
\text { Puddle }\end{array}$ & $\begin{array}{c}\text { Volume } \\
\left(\mathrm{m}^{3}\right)\end{array}$ & $\begin{array}{c}\text { Number } \\
\text { of months } \\
\text { with water } \\
\text { per year }\end{array}$ & $\mathrm{pH}$ & $\begin{array}{c}\text { Number of } \\
\text { predator } \\
\text { types }\end{array}$ & $\begin{array}{c}\text { Numbers of } \\
\text { predators }\end{array}$ & $\begin{array}{c}\text { Number of } \\
\text { species of } \\
\text { larvae }\end{array}$ & $\begin{array}{c}\text { Number of } \\
\text { species of } \\
\text { calling males }\end{array}$ & $\begin{array}{c}\text { Total } \\
\text { number of } \\
\text { species }\end{array}$ \\
\hline 1 & 6.09 & 5 & 7.48 & 4 & 37 & 4 & 2 & $\mathbf{5}$ \\
2 & 0.56 & 4 & 6.61 & 0 & 0 & 2 & 1 & $\mathbf{3}$ \\
3 & 0.46 & 5 & 7.20 & 1 & 8 & 1 & 3 & $\mathbf{4}$ \\
$4^{*}$ & 1.56 & 6 & 6.89 & 3 & 12 & 4 & 5 & $\mathbf{8}$ \\
5 & 16.31 & 4 & 7.24 & 4 & 8 & 4 & 6 & $\mathbf{4}$ \\
6 & 2.86 & 5 & 7.34 & 3 & 11 & 3 & 3 & $\mathbf{8}$ \\
\hline Total & & & & $\mathbf{5}$ & $\mathbf{7 6}$ & $\mathbf{8}$ & $\mathbf{8}$ & $\mathbf{1 2}$ \\
\hline
\end{tabular}

predators (as independent variables) to the number of species of tadpoles, calling males, and species of tadpoles plus calling males (as dependent variables). Separate analyses were conducted for tadpoles, calling males, and tadpoles plus calling males. We used only the data from the first rainy season for the plasticlined control puddles in this analysis, because the tarpaulins represent an additional variable. Had these puddles not remained with the tarpaulins, they probably would not have retained water long enough for colonization to occur, as evidenced in the first year. We also conducted a stepwise, multiple linear regression to test whether the independent variables puddle volu$\mathrm{me}$, permanency, $\mathrm{pH}$, and distance from the colonizer source related to number of tadpole predator richness, and another to test whether these same independent variables related to tadpole predator abundance.

Because we found few natural puddles at the study site, and many additional variables (e.g., vegetation cover, puddle morphometry; Bunnell and Zampella, 1999; Marsh and Borrell, 2001) may influence anuran colonization in these puddles, there were insufficient data to determine statistically the main factors determining anuran colonization of the puddles.

\section{Results}

In the six natural puddles (Table 1), we found (1) calling males and tadpoles of Scinax duartei, S. squalirostris, Leptodactylus jolyi, $L$. syphax, and Odontophrynus americanus, (2) calling males of Leptodactylus cunicularius, $L$. furnarius, L. fuscus, and Physalaemus cuvieri; and (3) tadpoles of Leptodactylus camaquara, L. cf. ocellatus, and Physalaemus evangelistai.

In the source puddle (Puddle 4), we found calling males of Scinax duartei, S. squalirostris, Leptodactylus furnarius, L. jolyi, Physalaemus cuvieri, and tadpoles of S. duartei, Leptodactylus jolyi, Odontophrynus americanus, and Physalaemus evangelistai. We also heard males of Hyla albopunctata and $H$. cipoensis calling from the nearby stream. During the additional sampling period while we conducted the experiment and continued sampling Puddle 4, we also found tadpoles of Phrynohyas venulosa and an egg mass of Physalaemus cuvieri in the source puddle. This and some experimental puddles located nearby apparently were connected to the stream during heavy rains because a small fish (Trychomycterus brasiliensis Reinhardt, Trichomycteridae) appeared in one of the $2-\mathrm{m}$ artificial puddles $5 \mathrm{~m}$ from Puddle 4. 
Table 2 - Number of anuran species (tadpoles/calling males) found in artificial puddles at the Serra do Cipó (MG) and in Puddle 4 (see Table 1), from October 1999 to February 2001. Two artificial pools with $0.5 \mathrm{~m}$ diameter remained lined with a plastic tarpaulin during the second sampling period, keeping water for 6 months $(*)$.

\begin{tabular}{|c|c|c|c|c|c|c|c|c|c|}
\hline $\begin{array}{l}\text { Artificial } \\
\text { puddles } \\
\text { (by size) } \\
\text { (m) }\end{array}$ & $\begin{array}{l}\text { Volume } \\
\qquad\left(\mathrm{m}^{3}\right)\end{array}$ & $\begin{array}{l}\text { Distance } \\
\text { from } \\
\text { the } \\
\text { natural } \\
\text { puddle } \\
\text { (m) }\end{array}$ & $\begin{array}{l}\text { Number of } \\
\text { months } \\
\text { with } \\
\text { water per } \\
\text { year }\end{array}$ & $\mathrm{pH}$ & $\begin{array}{l}\text { Number } \\
\text { of } \\
\text { predator } \\
\text { types }\end{array}$ & $\begin{array}{l}\text { Number } \\
\text { of } \\
\text { predators }\end{array}$ & $\begin{array}{c}\text { Number } \\
\text { of } \\
\text { species } \\
\text { of } \\
\text { larvae }\end{array}$ & $\begin{array}{c}\text { Number } \\
\text { of } \\
\text { species } \\
\text { of } \\
\text { calling } \\
\text { m ales }\end{array}$ & $\begin{array}{c}\text { Total } \\
\text { Number } \\
\text { of } \\
\text { species }\end{array}$ \\
\hline \multirow[t]{6}{*}{0.5} & 0.05 & 5 & 2 & 6.89 & 2 & 4 & 0 & 1 & 1 \\
\hline & & 10 & 6 & 7.07 & 2 & 5 & 1 & 0 & 1 \\
\hline & & 20 & 2 & 7.08 & 0 & 0 & 0 & 0 & 0 \\
\hline & & 40 & 6 & 7.08 & 2 & 3 & 1 & 0 & 1 \\
\hline & & 80 & $1 / 6^{*}$ & - & 0 & 0 & 0 & 0 & 0 \\
\hline & & 160 & $1 / 6^{*}$ & 7.04 & 0 & 0 & 0 & 0 & 0 \\
\hline Total & & & & & 4 & 12 & 2 & 1 & 3 \\
\hline \multirow[t]{6}{*}{1.0} & 0.20 & 5 & 6 & 7.07 & 3 & 5 & 3 & 2 & 3 \\
\hline & & 10 & 6 & 7.07 & 3 & 11 & 1 & 0 & 1 \\
\hline & & 20 & 6 & 7.02 & 5 & 9 & 3 & 0 & 3 \\
\hline & & 40 & 1 & 7.05 & 3 & 3 & 0 & 0 & 0 \\
\hline & & 80 & 2 & 7.05 & 1 & 1 & 0 & 0 & 0 \\
\hline & & 160 & 0 & - & 0 & 0 & 0 & 0 & 0 \\
\hline Total & & & & & 7 & 29 & 3 & 2 & 4 \\
\hline \multirow[t]{6}{*}{2.0} & 0.79 & 5 & 6 & 7.08 & 3 & 15 & 3 & 2 & 4 \\
\hline & & 10 & 6 & 7.01 & 5 & 16 & 3 & 2 & 4 \\
\hline & & 20 & 5 & 7.08 & 3 & 13 & 2 & 1 & 2 \\
\hline & & 40 & 4 & 7.07 & 0 & 0 & 0 & 0 & 0 \\
\hline & & 80 & 4 & 7.11 & 2 & 5 & 2 & 0 & 2 \\
\hline & & 160 & 0 & - & 0 & 0 & 0 & 0 & 0 \\
\hline Total & & & & & 6 & 49 & 5 & 2 & 5 \\
\hline $\begin{array}{l}\text { Total for } \\
\text { all pools }\end{array}$ & & & & & 7 & 90 & 6 & 3 & 7 \\
\hline Natural & & & 1 & & & & & & \\
\hline $\begin{array}{c}\text { puddle } \\
\text { (puddle 4) }\end{array}$ & 1.56 & & 6 & 6.89 & 4 & 14 & 4 & 3 & 6 \\
\hline
\end{tabular}

The tadpoles found in the artificial puddles occurred in large numbers and all the taxa, except Leptodactylus syphax, typically are found as larvae in standing water. Therefore, we assumed that the tadpoles we observed resulted from adults having bred at the puddles, rather than the larvae having been washed in from the stream by floods. Leptodactylus syphax tadpoles usually occupy permanent or temporary streams; however, their occurrence in three different 
Table 3 - Number of anuran species that colonized artificial pools of different sizes and located at different distances from a potential colonizer source (the natural Puddle 4).

\begin{tabular}{|c|c|c|c|c|c|c|}
\hline \multirow{2}{*}{$\begin{array}{c}\text { Distance from } \\
\text { Puddle } 4 \\
\text { (m) }\end{array}$} & \multicolumn{3}{|c|}{ Pool diameter (m) } & \multirow{2}{*}{$\begin{array}{l}\text { Anuran } \\
\text { Species } \\
\text { total }\end{array}$} & \multirow{2}{*}{$\begin{array}{l}\text { Number of } \\
\text { predator types }\end{array}$} & \multirow{2}{*}{$\begin{array}{l}\text { Total number } \\
\text { of predators }\end{array}$} \\
\hline & 0.5 & 1.0 & 2.0 & & & \\
\hline 5 & 1 & 3 & 4 & 4 & 4 & 24 \\
\hline 10 & 1 & 1 & 4 & 5 & 6 & 32 \\
\hline 20 & 1 & 3 & 2 & 4 & 5 & 22 \\
\hline 40 & 1 & 0 & 0 & 1 & 4 & 6 \\
\hline 80 & 0 & 0 & 2 & 2 & 3 & 6 \\
\hline 160 & 0 & 0 & 0 & 0 & 0 & 0 \\
\hline Total & 3 & 4 & 5 & 7 & 7 & 90 \\
\hline
\end{tabular}

puddles, along with their absence in the puddles located among those occupied, suggest that they probably came directly from their nests rather than having been carried from the nearby stream by floods.

In the artificial puddles, we found calling males and tadpoles of Leptodactylus jolyi, Odontophrynus americanus, and Physalaemus cuvieri. There were calling males of Scinax duartei and tadpoles of Leptodactylus labyrinthicus and L. syphax.

The puddles with plastic liners retained water for the entire rainy season, but no anurans colonized them. Abundant growths of algae and fungi fouled the water, and this condition may be unsuitable for the development of anuran eggs and tadpoles. We found dead egg clutches attacked by fungi at Serra do Cipó in temporary stream backwaters that kept some standing water during the dry season. The water in all natural puddles having anuran eggs and tadpoles always was clear. The $\mathrm{pH}$ of the artificial puddles varied from 6.89 to 7.11 among puddles (Table 2).

The number of anuran species (including both tadpoles and calling males) that colonized the artificial experimental puddles are positively correlated to the number of types of potential tadpole predators $(\mathrm{R}=0.977 ; \mathrm{P}=0.014$; Figure
2) after the variables distance from source, $\mathrm{pH}$, and predator abundance are eliminated through the stepwise procedure. Puddle volume ( $\mathrm{P}=$ $0.094)$ and permanency $(P=0.129)$ also were included in the model. The number of species of tadpoles in the puddles are positively correlated to number of types of potential tadpole predators and puddle permanency $(\mathrm{R}=0.877 ; \mathrm{P}$ $=0.020$ and $P=0.037$, respectively; Figures 2 and 3). Puddle volume also was included in the model $(P=0.140)$ and the remaining variables were eliminated through the stepwise procedure. The number of calling males are positively related to abundances of potential tadpole predators $(\mathrm{R}=0.640 ; \mathrm{P}=0.010$; Figure 4$)$. Potential tadpole predator richness increases with puddle permanency $(\mathrm{R}=0.700 ; \mathrm{P}=0.006$; Figure 5), after elimination of the variables puddle volume and isolation. Potential tadpole predator abundance increases with puddle permanency and volume $(R=0.806 ; P=0.009$ and $\mathrm{P}=0.041$, respectively; Figure 5), with only isolation having been eliminated from the analysis.

\section{Discussion}

Because natural, temporary puddles are 


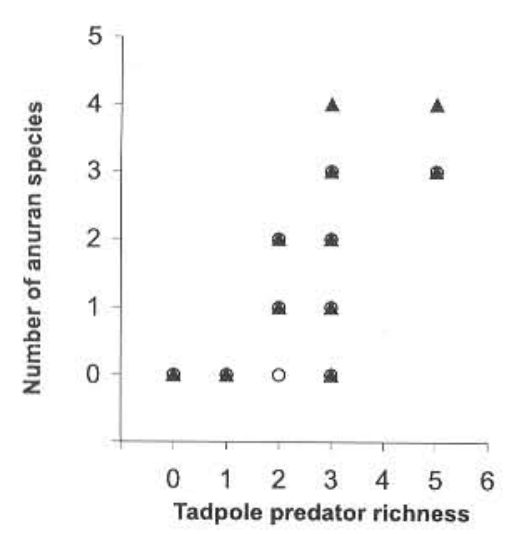

Figure 2 - Relation between the number of tadpoles (O) and anuran species (tadpoles plus calling males) (A) and tadpole predator types found in 18 experimental artificial puddles at the Serra do Cipó, Southeastern Brazil.

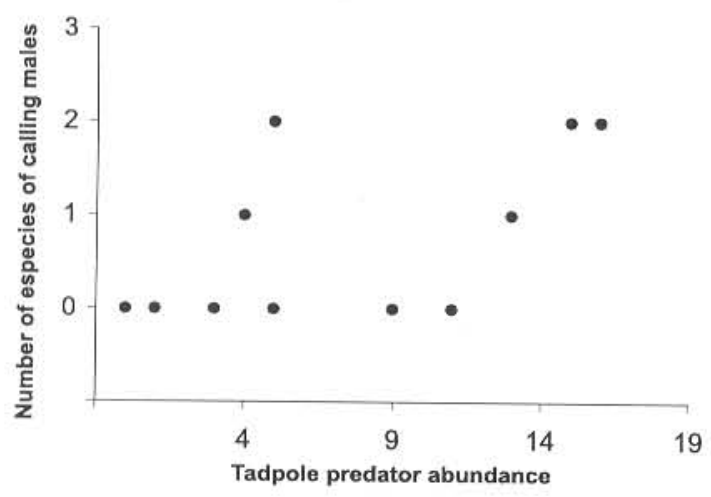

Figure 4-Relation between the number of species of calling males and tadpole predator types found in 18 experimental artificial puddles at the Serra do Cipo, Southeastern Brazil.

uncommon at the study site and are highly variable in physical and biological properties, we found no correlates of these properties with anuran species richness. Wild (1996) failed to detected correlations among physical features (water temperature, dissolved oxygen, and $\mathrm{pH}$ ) and tadpole species richness, evenness, or

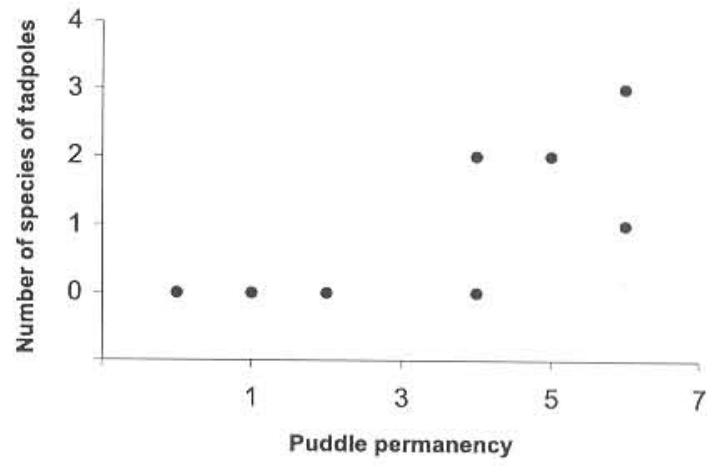

Figure 3 - Relation between the number of tadpole species and puddle permanency (number of months with water per year) in 18 experimental artificial puddles at the Serra do Cipó, southeastern Brazil.

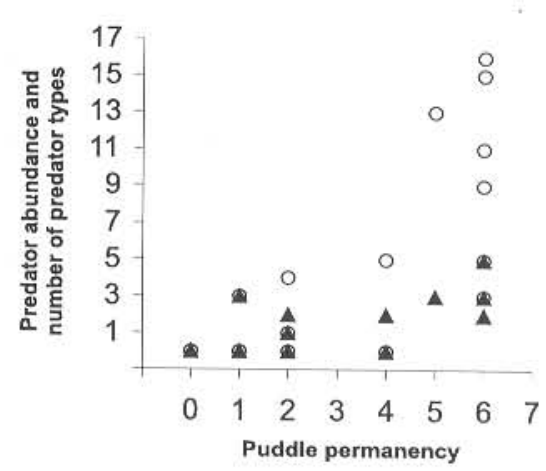

Figure 5 - Relation between puddle permanency (number of months with water) and richress $(\boldsymbol{A})$ and abundance $(\mathrm{O})$ of potential tadpole predators found in the 18 experimental artificial puddles at the Serra do Cipó, Southeastern, Brazil.

diversity in four Amazonian ponds. If such correlations exist, a larger sample size of ponds may be necessary to reveal them.

In the natural puddles that we studied at the Serra do Cipó, many species that were not present in the first sampling year appeared in the second sampling year (e.g., Leptodactylus 
syphax and Odontophrynus americanus in Puddle 1, L. syphax in Puddle 2, L. cf. ocellatus in Puddle 5, Scinax duartei in Puddle 6); these occurrences may indicate colonization events. It is also possible that some years prove unsuitable for reproduction by certain species owing to some combination of environmental features; such species may remain in the area without reproducing. Estimates of the rates of dispersal and colonization of new breeding sites by anurans in patchy environments are needed. Anuran dispersal to new reproductive sites is difficult to estimate by standard mark-recapture studies, because it is extremely difficult to census all possible dispersal destinations (Porter and Dooley, 1993). This is especially of sites such as the montane fields of the Serra do Cipó, where many ephemeral habitats are used by anurans for reproduction in ways that vary annually (I. Sazima, unpubl. data; PCE, pers. obs.). A molecular approach might produce useful estimations of migration rates among populations (Parker et al., 1998) and is currently being applied to estimate migration rates of Hyla saxicola among breeding sites at the Serra do Cipó (PCE, unpubl. data).

All the puddles studied are isolated, but many anuran species that use them for reproduction also can use swamps and stream pools that may serve as colonizing sources. Based on our experiment, it is clear that distances up to 80 $\mathrm{m}$ are traversed with ease by some dispersing anurans. Leptodactylus labyrinthicus and Physalaemus cuvieri occupied a puddle located $80 \mathrm{~m}$ from the source, and this puddle was the only one at this distance that kept water for more than two consecutive sampling months. The other puddles located $80 \mathrm{~m}$ from the source may not have retained water for a sufficient length of time for colonization to occur. Physalaemus cuvieri may have used "stepping stone" dispersal to reach the colonized puddle, but in spite of calling from some puddles closer to the natural colonization source, the species reproduced only at the most distant puddle containing water. This seems to indicate that some kind of habitat selection occurred. L. labyrinthicus may have come from even greater distances, because we did not find this large species $(S V L=15 \mathrm{~cm})$ with a loud mating call within a $200-\mathrm{m}$ radius experimental area. Thus, the most distant artificial puddles may have not been colonized because they did not retain water long enough for colonization to occur; thus, puddle permanency, rather than isolation, is the most likely limiting factor. Túngara frogs (Physalaemus pustulosus) disperse from breeding sites and gradually find new sites at greater and greater distances (Marsh et al., 1999). At least 30\% of these frogs regularly disperse between ponds 50$200 \mathrm{~m}$ apart, and the species is known to move more than $200 \mathrm{~m}$ from one pond to another (Marsh et al., 1999). Túngara frogs also reproduce in temporary bodies of water and such dispersal abilities may be widespread among anurans that use ephemeral habitats.

The lengths of the transects through which artificial puddles were positioned might not have posed any difficulties to dispersing anurans, but water turbidity and the presence of fungi and decomposing matter seemed to prevent anuran oviposition in the puddles that remained lined by tarpaulins. High concentrations of organic acids can cause embryonic mortality in anurans (Freda et al., 1990), and low $\mathrm{pH}$ can facilitate fungal infections (Gascon and Planas, 1986). In the remaining artificial puddles, the small range of $\mathrm{pH}(0.22)$ values probably was not important. The amount of emergent herbaceous vegetation (Bunnell and Zampella, 1999) influences tadpole richness in natural puddles; however, all artificial puddles had bare soil on the bottom were surrounded by homogeneous herbaceous vegetation and lacked submerged vegetation. These features of the artificial puddles may have prevented their colonization by Scinax duartei and $S$. squalirostris from Puddle 4, because these frogs prefer to call on shrubby vegetation and their tadpoles use microhabitats with aquatic or submerged vegetation (Eterovick and Sazima, 2000; PCE, pers. obs.). 
In experimental puddles, total number of potential tadpole predators are positively related to the number of species of calling males, and potential tadpole predator richness is the most useful parameter to explain the distribution of tadpoles and calling males plus tadpoles. It seems that males do not avoid puddles that represent a higher predation risk for their offspring, and may select puddles based on other features. These features also may attract the aquatic invertebrates that prey upon tadpoles. Skelly (1996) found average predator density and richness to increase with pond permanency, as did we. Tadpoles, as well as their predators, have higher species richness in puddles that retain water for longer periods of time.

The longer a puddle persists, the greater the opportunity for anuran colonization. We did not observe a temporal distribution of colonization however, because it occurred mostly in December, when most puddles were full. If females are more sensitive than males to choice of reproductive sites, then the reproductive success of males calling from more permanent puddles would be greater than those calling from ephemeral sites. Alternatively, clutches deposited in puddles that are more permanent may have been more successful, because tadpoles in more ephemeral puddles die from desiccation. This hypothesis seems less probable because if tadpoles had been present in such temporary puddles, we would have recorded them while the puddles retained the water. The positive correlation between the number of predator types and the number of species of tadpoles may be a consequence of longer puddle permanency, which is advantageous for both predators and prey. Indeed, both potential tadpole predator richness and abundance increases with puddle permanency. The only anuran species found in a puddle that kept water for two months was Physalaemus cuvieri; however, no egg clutches or tadpoles were found. The most temporary puddle in which we found tadpoles included Leptodactylus labyrinthicus and $P$. cuvieri, the tadpoles of which develop in one and one to two months, respectively (PCE, unpubl. data). Tadpoles are subject to a trade-off between their abilities to garner resources and avoid predation at the same time (Skelly, 1996). Populations living in temporary waters must be adapted to a chemically and physically unstable medium, and must be able to reproduce and develop in compressed time frames in a fluctuating environment (Bonner et al., 1997). Species having rapid developmental rates may be able to use more ephemeral habitats and thereby avoid a higher predation risk.

In habitats with low predictability (e.g., temporary bodies of water), community structure probably is governed by stochastic processes (Bonner et al., 1997). Therefore, it is erroneous to make generalizations about a "typical" temporary pool ecosystem, because each ephemeral pool is a unique habitat. Moreover, reproductive success of anuran populations in such habitats may vary greatly from year to year (Bonner et al., 1997). In spite of this unpredictability and stochasticity, a relationship between puddle permanency and tadpole species richness could be detected in this study, and puddle permanency seems to be a key factor influencing the composition of anuran communities in temporary habitats at the Serra do Cipó.

\section{Acknowledgements}

We thank I. S. Barros, M. Callisto, M. D. C. Goulart, J. F. Gonçalves-Jr., and L. B. Nascimento for help in field work, R. Altig, C. Gascon, C. F. B. Haddad, and W. R. Heyer for critical revision of the manuscript, all the staff of the Parque Nacional da Serra do Cipó for their kindness and for providing us with lodging during the field work; the Sansuy Indústria de Plásticos for providing the plastic tarpaulins for the experiment with artificial puddles, the Instituto Nacional do Meio Ambiente e dos Recursos Naturais Renováveis (Ibama) for the license to conduct this work at the Parque Nacional da 
Serra do Cipó; the Programa de Demanda Social (Capes), the Fundação de Desenvolvimento da Pesquisa (Fundep), and the Post Graduation Program in Ecologia, Conservação e Manejo de Vida Silvestre for financial support.

\section{References}

Bunnell, J. F. and R. A. Zampella. 1999. Acid water anuran pond communities along a regional forest to agrourban ecotone, Copeia 1999: 614-627.

Bonner, L., W. Diehl, and R. Altig. 1997. Physical, chemical and biological dynamics of five temporary dystrophic forest pools in central Mississippi. Hydrobiologia 353: 77-89.

Borror, D. J., C. A. Triplehorn, and N. F. Johnson. 1992. An Introduction to the Study of Insects. Sixth edition. Harcourt Brace College Publishers, Philadelphia. 875 pp.

Eterovick, P. C. and 1. Sazima. 2000. Structure of an anuran community in a montane meadow in southeastern Brazil: effects of seasonality, habitat, and predation. Amphibia-Reptilia 21: 439-461.

Evans, M., C, Yáber, and J-. M. Hero. 1996. Factors influencing choice of breeding site by Bufo marinus in its natural habitat. Copeia 1996: 904-912.

Freda, J., V. Cavdek, and D. G. McDonald. 1990. Role of organic complexation in the toxicity of aluminum to Rana pipiens embryos and Bufo americanus tadpoles. Canadian Journal of Fisheries and Aquatic Sciences 47: 217-224.

Gascon, C. and D. Planas. 1986. Spring pond water chemistry and the reproduction of the wood frog Rana sylvatica. Canadian Journal of Zoology 64: 543-550.

Leuven, R. S. E. W., C. den Hartog, M. M. C. Christiaans, and W. H. C. Heijligers, 1986. Effects of water acidification on the distribution pattern and the reproductive success of amphibians. Experientia 42: 495-503.

Marsh, D. M. and B. J. Borrell. 2001. in press. Flexible oviposition strategies in túngara frogs and their implications for tadpole spatial distributions. Oikos 92 .
Marsh, D. M., E. H. Fegraus, and S. Harrison. 1999. Effects of breeding pond isolation on the spatial and temporal dynamics of pond use by the tungara frog. Physalaemus pustulosus. Journal of Animal Ecology 68: $804-814$.

Morin, P. J. 1983. Predation, competition, and the composition of larval anuran guilds. Ecological Monographies 53: 119-138.

Parker, P. G., A. A. Snow, M. D. Schug, G. C. Booton, and P. A. Fuerst. 1998. What molecules can tell us about populations: choosing and using a molecular marker. Ecology 79: 361-382.

Porter, J. H. and J. L., Dooley Jr̂. 1993. Animal dispersal patterns: a reassessment of simple mathematical models. Ecology 74: 2436-2443.

Resetarits, W. J., Jr. and H. M. Wilbur. 1989. Choice of oviposition site by Hyla chrysoscelis: role of predators and competitors. Ecology 70: 220-228.

Roth, A. H., and J. F. Jackson. 1987. The effect of pool size on recruitment of predatory insects and on mortality in a larval anuran. Herpetologica 43 : $224-232$.

Sazima, I., and W. C. A. Bokermann. 1977. Anfíbios da Serra do Cipó, Minas Gerais, Brasil. 3: Observaçōes sobre a biologia de Hyla alvarengai Bok. (Anura, Hylidae). Revista Brasileira de Biologia 37: 413-417.

Seale, D. B, 1980. Influence of amphibian larvae on primary production, nutrient flux, and competition in a pond ecosystem. Ecology 61: 1531-1550.

Skelly, D. K. 1996. Pond drying, predators, and the distribution of Pseudacris tadpoles. Copeia 1996: $599-605$

Skelly, D. K. 1997. Tadpole communities. American Scientist 85: 36-45.

SYSTAT for Windows. 1998. Statistics, Version 6 Edition. Evanston, IL: SYSTAT, Inc.

Werner, E. E. and K. S. Glennemeier. 1999. Influence of forest canopy cover on the breeding pond distributions of several amphibian species. Copeia 1999: 1-12.

Wild, E. R. 1996. Natural history and resource use of four Amazonian tadpole assemblages. Occasional Papers of the Museum of Natural History of the University of Kansas 176: 1-59. 